\title{
Bartonella Species and Trombiculid Mites of Rats from the Mekong Delta of Vietnam
}

\author{
Hoang Kim Loan,' Nguyen Van Cuong,, Ratree Takhampunya, ${ }^{3}$ Kewalin Klangthong, ${ }^{3}$ Lynn Osikowicz, \\ Bach Tuan Kiet, ${ }^{5}$ James Campbell, ${ }^{2}$ Juliet Bryant, ${ }^{2}$ Sommai Promstaporn, ${ }^{3}$ Michael Kosoy, ${ }^{4}$ \\ Nguyen Van Hoang, ${ }^{5}$ Serge Morand, ${ }^{6}$ Yannick Chaval, ${ }^{6}$ Vo Be Hien, ${ }^{5}$ and Juan Carrique-Mas ${ }^{2}$
}

\begin{abstract}
A survey of Bartonella spp. from 275 rats purchased in food markets $(n=150)$ and trapped in different ecosystems (rice field, forest, and animal farms) $(n=125)$ was carried out during October, 2012-March, 2013, in the Mekong Delta of Vietnam. The overall Bartonella spp. prevalence detected by culture and PCR in blood was 14.9\% (10.7$19.1 \%$ ), the highest corresponding to Rattus tanezumi (49.2\%), followed by Rattus norvegicus (20.7\%). Trapped rats were also investigated for the presence and type of chiggers (larvae of trombiculid mites), and Bartonella spp. were investigated on chigger pools collected from each rat by RT-PCR. A total of five Bartonella spp. were identified in rats, three of which (B. elizabethae, B. rattimassiliensis, and B. tribocorum) are known zoonotic pathogens. Among trapped rats, factors independently associated with increased prevalence of Bartonella spp. included: (1) Rat species (R. tanezumi); (2) the number of Trombiculini-Blankaartia and Schoengastiini-Ascoschoengastia mites found on rats; and (3) the habitat of the rat (i.e., forest/fields vs. animal farms). The prevalence of Bartonella infection among chiggers from Bartonella spp.-positive $R$. tanezumi rats was 5/25 (25\%), compared with 1/27 (3.7\%) among Bartonella spp.-negative $R$. tanezumi rats (relative risk $[\mathrm{RR}]=5.4,95 \%$ confidence interval $[\mathrm{CI}]$ 0.68-43.09). The finding of Bartonella spp.-positive chiggers on Bartonella spp.-negative rats is strongly suggestive of a transovarial transmission cycle. Rats are ubiquitous in areas of human activity and farms in the Mekong Delta; in addition, trapping and trading of rats for food is common. To correctly assess the human risks due to rat trapping, marketing, and carcass dressing, further studies are needed to establish the routes of transmission and cycle of infection. The widespread presence of these zoonotic pathogens in rats and the abundance of human-rat interactions suggest that surveillance efforts should be enhanced to detect any human cases of Bartonella infection that may arise.
\end{abstract}

Key Words: Bartonella—Rattus—Chiggers—Vietnam.

\section{Introduction}

T He Genus Bartonella CONTAINS InTRACEllular Gramnegative bacteria considered to be opportunistic human pathogens, although some species are capable of causing disease in healthy people. Infections with Bartonella spp. are associated with a remarkable variety of clinical symptoms, ranging from transitory febrile disease, to severe vascular dysfunction and endocarditis (Maguiña and Ordaya 2010). Although there is a degree of host specificity, Bartonella spp. have a wide range of mammalian animal hosts, including felines, canines, primates, rodents, bats, and shrews (Breitschwerdt and Kordick 2000, Chomel and Kasten 2010). Depending on the Bartonella and host species, transmission between vertebrate hosts, including humans, occurs through arthropod vectors such as ticks, fleas, sand flies, and lice

\footnotetext{
${ }^{1}$ Institute Pasteur, Ho Chi Minh City, Vietnam.

${ }^{2}$ Oxford University Clinical Research Unit, Vietnam.

${ }^{3}$ AFRIMS, Bangkok, Thailand.

${ }^{4}$ Centre for Disease Control, Fort Collins, Colorado.

${ }^{5}$ Sub-Department of Animal Health, Dong Thap, Vietnam.

${ }^{6}$ Institute Nationale de la Recherche Agricole, Montpellier, France.

(C) The Author(s) 2015; Published by Mary Ann Liebert, Inc. This Open Access article is distributed under the terms of the Creative Commons License (http://creativecommons.org/licenses/by/4.0), which permits unrestricted use, distribution, and reproduction in any medium, provided the original work is properly credited.
} 
(Boulouis et al. 2005, Chomel and Kasten 2010, Kamani et al. 2013). Cases of infection with Bartonella spp. in humans have increasingly been reported from East and Southeast Asian countries (Kosoy et al. 2008, Paitoonpong et al. 2008, Bhengsri et al. 2010, Kosoy et al. 2010, Pachirat et al. 2011, Bai et al. 2012, Lim et al. 2012). Recent studies carried out in a number of Southeast Asian countries have detected a range of Bartonella spp. in rats (Castle et al. 2004, Bai et al. 2009, Bhengsri et al. 2010, Kosoy 2010, Loan et al. 2011). In Vietnam, a 2011 study on rats indicated an overall prevalence for Bartonella spp. of $19.2 \%$, including zoonotic species such as B. elizabethae, and B. rattimassiliensis (Loan et al. 2011), both of which have been associated with febrile disease in southeast Asia (Kosoy et al. 2010). Data from Thailand suggest that exposure to ticks, outdoor activities, and exposure to rats are factors associated with human infection with Bartonella spp. (Bhengsri et al. 2010).

Chiggers are larval mites of the family Trombiculidae and are thought to be the most common ectoparasites on rats in the Mekong Delta, in contrast with ticks, lice, and fleas, which are rarely seen (unpublished information). The life cycle of trombiculid mites consists of three active stages-larvae (chiggers), nymphs, and adults. The nymph and adult stages are free-living, whereas the larvae are parasitic on a wide range of animals, including rats, squirrels, shrews, and birds (Traub and Wisseman 1974). In rats, chiggers are usually found attached to the tragus of the ear. About 350 species of chiggers have been described in Southeast Asia (Nadchatram and Dohany 1974). Chiggers of the genus Leptotrombidium are vectors of Orientia tsutsugamushi, the causative agent of scrub typhus (Traub and Wisseman 1974, Lerdthusnee et al. 2002). In Thailand, chiggers of the genera Leptotrombidium, Schoengastia, and Blankarrtia collected from rats were found to harbor zoonotic Bartonella tamiae (Kabeya et al. 2010).

The prevalence of Bartonella spp. in different rat species and their potential association with their ectoparasites have not been investigated in the Mekong Delta region of Vietnam, a region where rats are a commonly captured after rice harvests and sold for food (Phan et al. 2005). We conducted a survey of rats, including both specimens sold in live in markets as well as rats captured across the Mekong Delta with the aims to: (1) Investigate the prevalence and species diversity of Bartonella spp. in different species of rats; (2) characterize the burden and species of chiggers in rats and the prevalence of Bartonella spp. in the chiggers themselves; and (3) investigate variables associated with prevalence of Bartonella spp. (rat species, stage of development, as well as chigger burden and species).

\section{Materials and Methods}

\section{Rat collection and processing}

Rats were purchased from five provincial and district markets, in addition to four local traders (i.e., nine sources) located in five provinces of the Mekong Delta (Dong Thap, Tien Giang, An Giang, Vinh Long, and Can Tho) ( 30 per province) during October of 2012. Rat trapping was carried out in different locations in the province of Dong Thap during March, 2013. A total of 30 lines (one per location) of 10 live cage metal tomahawk traps were set up, checked for rats trapped, and reset over 10 subsequent mornings (totaling about 3000 trap-days). Traps were placed in farm sites where poultry and pigs were kept $(n=20)$, as well as in crop fields (rice) and forest locations $(n=10)$. Traps with a rat inside were brought back to the laboratory and were replaced by a new trap. On the day of purchase/catching, the following procedures were carried out on all rats: (1) Humane culling by overdose of inhalant anesthetic (isoflurane) following American Veterinary Medical Association (AVMA) guidelines (American Veterinary Medical Association 2007); (2) measurement of main biological and morphometric parameters (weight, sex, body length, tail length, foot length, ear length, skull length, ear length, fur color, reproductive status) to allow species identification; (3) postmortem aseptic collection of $1-3 \mathrm{~mL}$ of whole blood by cardiac puncture; and (4) collection of one ear from each animal, by cutting it from the base and placing into a $5-\mathrm{mL}$ universal tube with $70^{\circ} \mathrm{C}$ ethanol. Detailed methods for sample collection are described elsewhere (Ceropath 2011).

\section{Rat species identification}

The rat species identification was carried out on the basis of morphological characteristics. One rat representative of each batch (markets) and two to three of each species identified were confirmed by amplification of a conserved housekeeping gene (cytochrome oxidase subunit I, COI) using PCR followed by molecular sequencing of the product and blasting using the RatSEA barcoding tool (www.ceropath .org/barcoding_tool/ratsea).

\section{Identification of trombiculid mites}

Rat ears were placed on separate Petri dishes containing $70 \%$ ethanol, and chiggers were counted under a stereomicroscope (magnification, $20 \times$ ) after being removed using a fine needle. Chiggers were washed several times with distilled water to remove alcohol. Chiggers were then submerged in a drop of mounting fluid (Berlese's fluid-gum chloral, TCS Biosciences Ltd, UK) that had previously been placed on a glass slide. Slides were dried overnight using an incubator at $40^{\circ} \mathrm{C}$ and were then sealed with nail polish. Chiggers were examined using a phase-contrast microscope at $400 \times$ magnification. At least five chiggers from each ear were identified morphologically. The chigger mites were identified down to the subfamily-tribe-genus-subgenus based on published guidelines on Southeast Asian chiggers (Acari, Prostigmata, Trombiculidae) (Nadchatram and Dohany 1974).

\section{Culture of Bartonella spp. from rats}

Blood was cultured for Bartonella spp. in accordance with the Centers for Disease Control and Prevention (CDC) procedures (Ying et al. 2002, Bai et al. 2009). Briefly, whole blood was diluted 1:4 in brain heart infusion media containing 5\% amphotericin B (Sigma) to reduce the likelihood of fungal contaminants because of the slow growth of Bartonella spp. Diluted blood samples were pipetted onto Columbia agar (BioRad) plates containing 5\% fresh sheep blood previously screened to ensure absence of Bartonella spp. Plates were incubated at $35^{\circ} \mathrm{C}$ in an atmosphere of $5 \% \mathrm{CO}_{2}$ for up to 4 weeks. Plates were examined once per week for bacterial growth. Bacterial colonies were selected on the basis of colony morphology, size and shape, and Gram-staining characteristics, and were subcultured from initial plates and subsequent passages until a pure culture was obtained. 


\section{Confirmation of Bartonella spp. by PCR}

DNA extractions were performed on whole bacterial cells using a DNA extraction kit (QIAamp ${ }^{\circledR}$ DNA Mini Kit, cat. no. 51304, Qiagen, The Netherlands). Primers BhCS871.p and BhCS1137.n for amplification product of 379 of the citrate synthase ( $g$ ltA) gene of Bartonella were used. The PCR was carried out in a Techne 512 Thermal Cycler (Techne, UK) following program parameters - an initial denaturing at $95^{\circ} \mathrm{C}$ for $5 \mathrm{~min}$, and 35 cycles at $95^{\circ} \mathrm{C}$ for $1 \mathrm{~min}, 56^{\circ} \mathrm{C}$ for $1 \mathrm{~min}$, and $72^{\circ} \mathrm{C}$ for $1 \mathrm{~min}$. The PCR products were analyzed for the presence of amplicons of the correct size by electrophoresis in $1.5 \%$ agarose gels containing ethidium bromide.

\section{Detection of Bartonella spp. in chiggers}

Chiggers from each rat were pooled and subjected to genomic DNA extraction using a modified tissue protocol from QIAamp ${ }^{\circledR}$ DNA Mini Kit (Qiagen, Hilden, Germany). Chiggers were placed in a $1.5-\mathrm{mL}$ microcentrifuge tube and punctured with a fine needle. Ninety microliters of ATL tissue lysis buffer were added, and the sample was either processed immediately or stored at $-70^{\circ} \mathrm{C}$. Ten microliters of Proteinase $\mathrm{K}$ solution $(20 \mathrm{mg} / \mathrm{mL})$ were added, and the sample was incubated at $56^{\circ} \mathrm{C}$ for $3 \mathrm{~h}$. Subsequently, $100 \mu \mathrm{L}$ of AL buffer was added, and the sample was mixed by pulse-vortexing for $15 \mathrm{~s}$, followed by incubation at $70^{\circ} \mathrm{C}$ for $10 \mathrm{~min}$. Then $100 \mu \mathrm{L}$ of absolute ethanol was added, and the sample was mixed by pulse-vortexing for $15 \mathrm{~s}$. The sample was applied to a QIAamp spin column, and DNA was eluted in $50 \mu \mathrm{L}$ of AE buffer and stored at $-20^{\circ} \mathrm{C}$ until amplification. Detection of Bartonella in chiggers was performed by RT-PCR following a previously published protocol using Bartonella specific primers targeting the transfer-mRNA gene (ssrA) (Diaz et al. 2012).

\section{Bartonella species identification}

Sequences were analyzed using Lasergene v. 8 sequence analysis software (DNASTAR Inc., Madison, WI) to determine consensus of sequences for the amplified region of the gltA gene. Unique sequences obtained in this study were submitted to GenBank. The Clustal V program within the MegAlign module of Lasergene was used to compare homologous Bartonella spp. gltA sequences from the present study and from GenBank. A criterion of $\geq 96 \%$ homology to gltA was used to define groups (Gundi et al. 2009).

\section{Statistical analyses}

Bartonella spp. prevalence comparisons were performed using chi-squared tests. For trapped rats, the association between Bartonella spp. and the species, body length, type of habitat (farm vs. field/forest), and number of chiggers (logtransformed) was explored by multivariable logistic regression modeling. Body length was transformed into a binary variable (large/small) based on a cutoff determined by the $50 \%$ quantile for each species. Multivariable model building was carried out in a stepwise forward fashion starting with variables with the lowest $p$ value in univariable analyses (Hosmer et al. 2004). Interaction terms between all main effects remaining in the model were investigated. All data analyses were carried out using R software (www.r-project.org).

\section{Results \\ Prevalence of Bartonella spp. in rats}

A total of 275 rats were examined, of which 150 were purchased in markets and 125 were trapped. Five different rat species were identified: Rattus argentiventer $(n=104)$, Bandicota indica $(n=65), R$. tanezumi $(n=61), R$. norvegicus $(n=29)$, and $R$. exulans $(n=16)$. All rat species were present in both collections, except for $R$. exulans, which was not represented in the market collection. $R$. argentiventer was more represented in the market collection (58.7\%) than among trapped rats $(12.8 \%)$. In contrast, $R$. tanezumi was the most commonly trapped rat species $(41.6 \%)$, but represented only $6 \%$ of market rats. A total of 41 Bartonella strains were identified by culture and further confirmed by PCR. We did not observe any evidence of colonies of different morphology indicative for co-infection by different Bartonella species in the same rat.

The overall Bartonella spp. prevalence in rats was $14.9 \%$ (95\% confidence interval $[\mathrm{CI}]=10.7-19.1 \%$ ). The prevalence in rats purchased in markets was $8.7 \%$ compared with a prevalence of $22.4 \%$ among trapped rats $\left(\chi^{2}=9.08 ; p=0.002\right)$. The highest prevalence corresponded to R. tanezumi (49.2\%), followed by $R$. norvegicus $(20.7 \%)$. B. indica and $R$. argentiventer rats had $<5 \%$ Bartonella spp. prevalence, and all 16 R. exulans rats were Bartonella spp.-negative. For R. tanezumi, the Bartonella spp. prevalence was highest among rats trapped in fields/forests habitats $(63.6 \%)$, and lowest among rats trapped on farms $(21.0 \%)$ (Table 1).

Table 1. Prevalence of Bartonella spP. among Rats Purchased from Markets and Captured in Different Habitats of the Mekong Delta, October, 2012-March, 2013)

\begin{tabular}{|c|c|c|c|c|c|c|c|}
\hline \multirow[b]{2}{*}{ Site } & & \multicolumn{5}{|c|}{ Rat species } & \multirow[b]{2}{*}{ Total } \\
\hline & & B. indica & R. tanezumi & R. argentiventer & R. exulans & R. norvegicus & \\
\hline \multirow[t]{2}{*}{ Market } & Pos./Total & $1 / 44$ & $5 / 9$ & $3 / 88$ & - & $4 / 9$ & $13 / 150$ \\
\hline & $\%$ Pos. $(95 \% \mathrm{CI})$ & $2.3(0.0-6.7)$ & $55.5(23.1-88.0)$ & $3.4(0.0-7.2)$ & - & $44.4(12.0-76.9)$ & $8.7(4.2-13.2)$ \\
\hline \multirow[t]{2}{*}{ Farms } & Pos./Total & $0 / 10$ & $4 / 19$ & $0 / 14$ & $0 / 15$ & $2 / 18$ & $6 / 76$ \\
\hline & $\%$ Pos. $(95 \% \mathrm{CI})$ & 0.0 (N.C.) & $21.0(0-61.0)$ & 0.0 (N.C.) & 0.0 (N.C.) & $11.1(0-54.7)$ & $7.9(1.8-14.0)$ \\
\hline \multirow{4}{*}{$\begin{array}{l}\text { Field/ } \\
\text { forest } \\
\text { All rats }\end{array}$} & Pos./Total & $1 / 11$ & $21 / 33$ & $0 / 2$ & $0 / 1$ & $0 / 2$ & $22 / 49$ \\
\hline & $\%$ Pos. $(95 \% \mathrm{CI})$ & $9.1(0-65.4)$ & $63.6(43.1-84.2)$ & 0.0 (N.C.) & 0.0 (N.C.) & 0.0 (N.C.) & $44.9(30.9-58.8)$ \\
\hline & Pos./Total & $2 / 65$ & $30 / 61$ & $3 / 104$ & $0 / 16$ & $6 / 29$ & $41 / 275$ \\
\hline & $\%$ Pos. $(95 \% \mathrm{CI})$ & $3.1(0.0-7.3)$ & $49.2(36.6-61.7)$ & $2.9(0.0-6.1)$ & 0.0 (N.C.) & $20.7(5.9-35.4)$ & $14.9(10.7-19.1)$ \\
\hline
\end{tabular}

Pos., positive; CI, confidence interval; N.C., not calculated. 


\section{Distribution of Bartonella spp. in rats}

The species of Bartonella spp. was successfully determined for 32/41 Bartonella isolates (Fig. 1). In four cases, there was insufficient DNA available for sequencing, and, in five cases, the sequencing results resulted in nonspecific reactions. A total of five different species were identified. The most commonly identified species were Bartonella rattimassiliensis, $B$. tribocorum, and B. elisabethae (corresponding to $43.8 \%, 21.9 \%$, and $18.8 \%$ of rats infected with Bartonella spp.). B. rattimassiliensis and B. coopersplainensis were found only in $R$. tanezumi, whereas all other Bartonella spp. were found at least in two different host species (Table 2).

\section{Trombiculid larvae (chiggers) in trapped rats}

All rats investigated except one ( $R$. exulans) contained at least one chigger in their ears. The main trombiculid species identified corresponded to (tribe-genus-subgenus): Gahrliepiini-Gahrliepia-Walchia (GGW), SchoengastiiniAscoschoengastia (SA), Trombiculini-Blankaartia (TB), Schoengastiini-Schoengastia (SS), and TrombiculiniLeptotrombidium-Leptotrombidium (TLL). Overall counts were similar for all rat species (median six to eight). $R$. argentiventer rats had the highest chigger counts (median 8; interquartile range $[\mathrm{IQR}]=6.7-8.0)$, followed by $R$. tanezumi (median 7; IQR $=7-8$ ), whereas $R$. exulans had the lowest (median 6; IQR = 6.0-6.0) (Fig. 2).

\section{Prevalence of Bartonella spp. in chiggers}

Thirteen chigger pools of 124 (10.5\%) tested positive for Bartonella spp. A total of $6 / 28(21.4 \%)$ chigger pools from Bartonella spp.-positive rats tested positive, compared with 7/96 (7.3\%) pools from Bartonella spp.-negative rats (relative risk $[\mathrm{RR}]=2.97,95 \% \mathrm{CI}=1.09-8.12$ ). The prevalence of Bartonella spp. in chiggers from Bartonella spp.-positive
R. tanezumi rats was $5 / 25(25 \%)$, compared with $1 / 27(3.7 \%)$ among Bartonella spp.-negative $R$. tanezumi rats $(3.7 \%)$ $(\mathrm{RR}=5.4,95 \% \mathrm{CI}=0.68-43.09)$.

\section{Risk factors for Bartonella spp. positivity in rats}

Factors independently associated with Bartonella spp. prevalence in rats were: (1) Rat species ( $R$. tanezumi vs. other) (odds ratio $[\mathrm{OR}]=7.68$ ); (2) presence of SA and TB chiggers (log-transformed) $(\mathrm{OR}=2.23$ and $\mathrm{OR}=2.18$, respectively); and (3) type of habitat (rat trapped in field/ forest vs. trapped in a farm) $(\mathrm{OR}=3.20)$. Large rats (relative to the median for each species) had a higher risk of positivity $(\mathrm{OR}=2.55)$, although it was not significant $(p=0.103)$ and was therefore excluded from the model. Interaction terms between main effects were not significant $(p>0.05)$ (Table 3$)$.

\section{Size of R. tanezumi and Bartonella spp. prevalence}

Among $R$. tanezumi, there was a statistically significant association between body length and the probability of testing positive for Bartonella spp. $\left(\chi^{2}\right.$ for trend $=8.54, p=0.003$ ) (Fig. 3). In contrast, among $R$. norvegicus, the body length among Bartonella spp.-positive rats was smaller (189.0 mm) than for Bartonella spp.-negative individuals $(168.5 \mathrm{~mm})$ $(t=27.42 ; p<0.01)$.

\section{Discussion}

The observed overall Bartonella spp. prevalence in rats (14.9\%) was comparable with a previous study in Vietnam (19.2\%) (Loan et al. 2011) and with studies from other East and Southeast Asian countries (range 7.1-50\%) (Castle et al. 2004, Winoto et al. 2005, Lin et al. 2008, Angelakis et al. 2009, Bai et al. 2009, Hsieh et al. 2010, Loan et al. 2011, Jiyipong et al. 2012). Our study identified differences in Bartonella spp. prevalence by rat species, with the observed

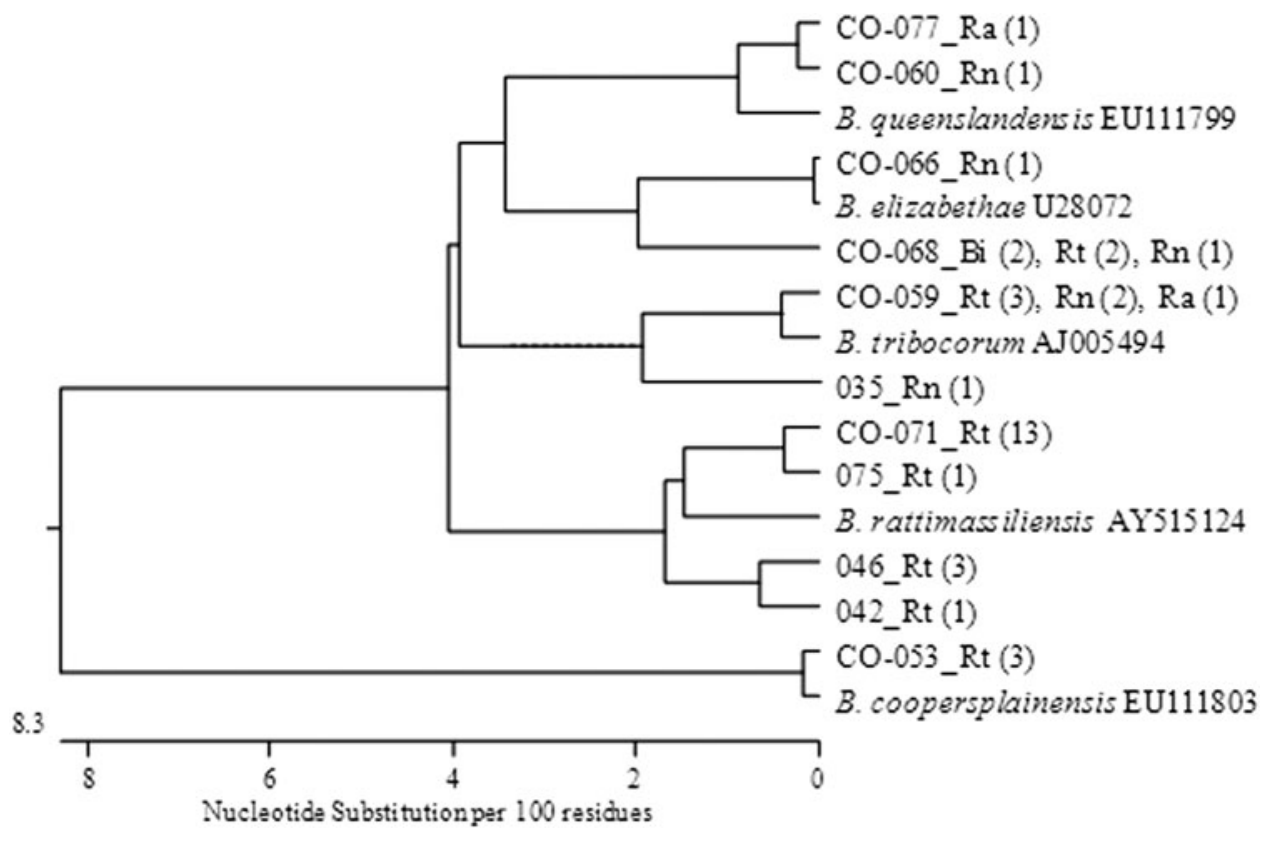

FIG. 1. Phylogenetic tree showing relationship between sequences of 32 Bartonella spp. analyzed for the amplified region of the gltA (Mekong Delta, Vietnam, October, 2012-March, 2013). 

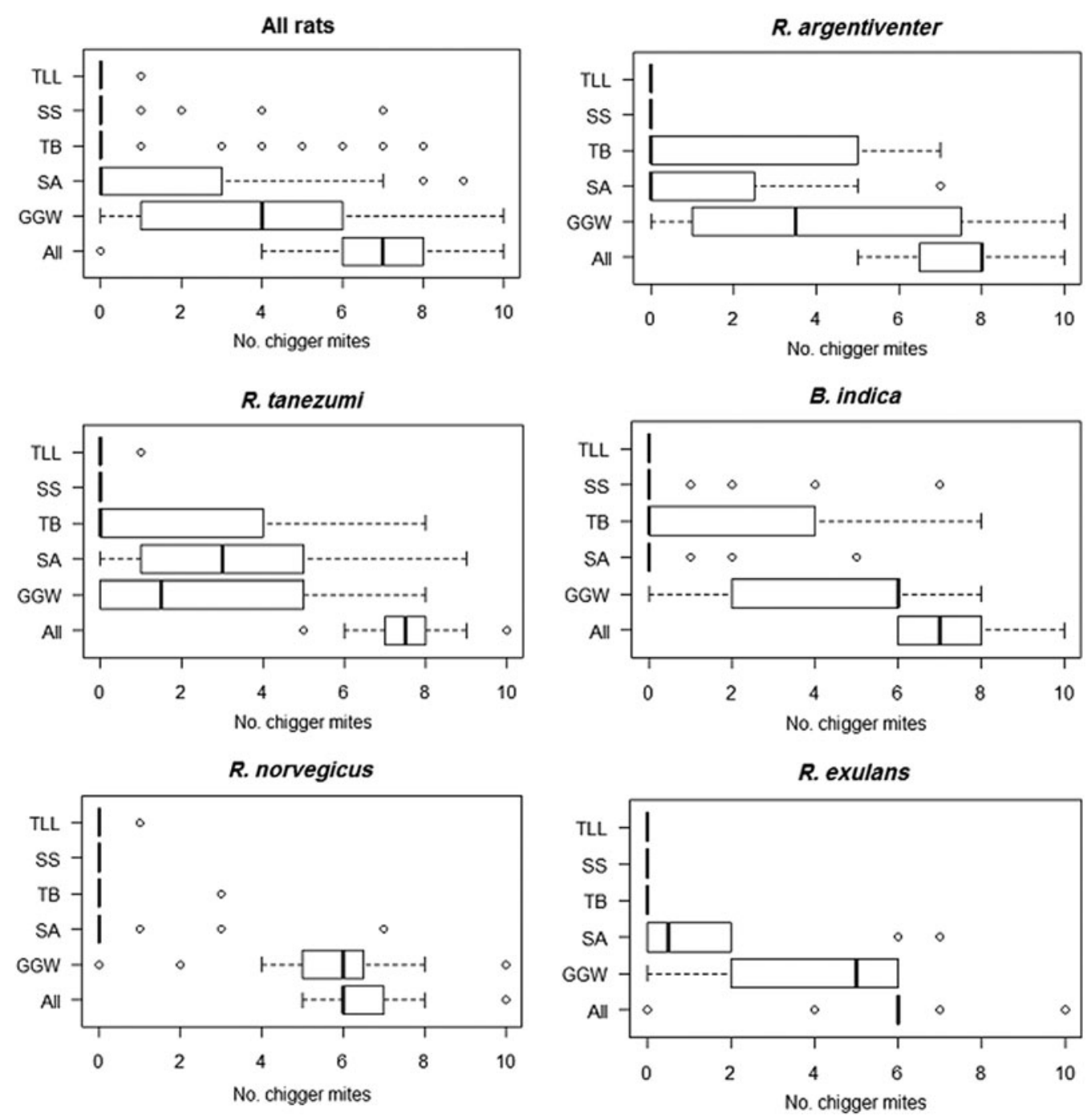

FIG. 2. Number of chigger mites per animal by rat species (counts on one ear). (Mekong Delta, Vietnam, October, 2012March, 2013). Tribe-genus-subgenus): TTL, Trombiculini-Leptotrombidium-Leptotrombidium; SS, Schoengastiini-Schoengastia; TB, Trombiculini-Blankaartia; SA, Schoengastiini-Ascoschoengastia; GGW, Gahrliepiini-Gahrliepia-Walchia.

highest prevalence $(\sim 50 \%)$ corresponding to $R$. tanezumi. Studies in the Southeast Asian region and China have confirmed high levels of Bartonella spp. infection among R. tanezumi (Ying et al. 2002, Winoto et al. 2005, Loan et al. 2011).

All five Bartonella species identified in our study (B. elizabethae, B. rattimassiliensis, B. tribocorum, B. queenlandensis, and $B$. coopersplainensis) have previously been identified in rats from the region (Castle et al. 2004, Angelakis et al. 2009, Bai et al. 2009, Loan et al. 2011, Jiyipong et al. 2012). Four species (B. elizabethae, B. rattimassiliensis, B. tribocorum, and $B$. queenlandensis) are phylogenetically close and belong to the $B$. elizabethae complex sensu lato as an assemblage of genospecies and strains associated with Old

TABle 2. Distribution of BARTONELLA SPP. IDENTIFIED IN RATS

(Mekong Delta, Vietnam, October, 2012-March, 2013)

\begin{tabular}{|c|c|c|c|c|c|c|}
\hline \multirow[b]{2}{*}{ Bartonella spp. } & \multicolumn{4}{|c|}{ Rat species } & \multirow[b]{2}{*}{ All rats } & \multirow[b]{2}{*}{ Percent $(\%)$} \\
\hline & R. tanezumi & R. norvegicus & B. indica & R. argentiventer & & \\
\hline B. rattimassiliensis & 14 & 0 & 0 & 0 & 14 & 43.8 \\
\hline B. tribocorum & 3 & 3 & 0 & 1 & 7 & 21.9 \\
\hline B. elizabethae & 2 & 2 & 2 & 0 & 6 & 18.8 \\
\hline B. coopersplainensis & 3 & 0 & 0 & 0 & 3 & 9.4 \\
\hline B. queenslandensis & 0 & 1 & 0 & 1 & 2 & 6.3 \\
\hline Total isolates & 22 & 6 & 2 & 2 & 32 & 100.0 \\
\hline
\end{tabular}


Table 3. Results from Multilevel Logistic REgRession Model With Significant Factors FOR BARTONELla SPP. PREVAlence AMONg Rats Trapped in Dong Thap, February-March, 2013

\begin{tabular}{lccc}
\hline & OR & 95\% CI & p value \\
\hline $\begin{array}{l}\text { Rattus tanezumi } \\
\quad \text { (baseline = other species) }\end{array}$ & 7.68 & $1.78-33.16$ & 0.006 \\
Log(SA + 1) & 2.23 & $0.98-5.11$ & 0.051 \\
Log(TB) + 1 & 2.18 & $1.02-4.69$ & 0.043 \\
Rat trapped in forest/ & 3.20 & $0.93-10.94$ & 0.064 \\
$\quad$ field (baseline = farm) & & & \\
\hline
\end{tabular}

Model intercept: -4.31 (standard error, 0.76).

OR, odds ratio; CI, confidence interval; SA, SchoengastiiniAscoschoengastia; TB, Trombiculini-Blankaartia.

World rats (Kosoy et al. 2012). Although phylogenetically more distant, B. coopersplainensis is also specific for Old World rats, but has been recently detected in an endemic Australian rat (Rattus leucopus) (Gundi et al. 2009). B. rattimassiliensis and $B$. coopersplainensis were found only in $R$. tanezumi, whereas B. tribocorum, B. queenslandensis, and $B$. elizabethae were harbored by rats of different species. B. rattimassiliensis, the most common Bartonella spp. identified in our study, has been isolated from $R$. norvegicus in Europe (Gundi et al. 2004) and from R. tanezumi trapped in other Mekong river countries (Jiyipong et al. 2012).

Three of the Bartonella spp. described (B. elizabethae, B. rattimassiliensis, and B. tribocorum) have been associated with human febrile illness in Thailand and have been linked epidemiologically to exposure to rats (Kosoy et al. 2010). Importantly, one of the B. elizabethae strains isolated from a $R$. norvegicus had an identical gltA gene to the strain isolated from a human endocarditis patient in Massachusetts (Daly et al. 1993). Other Bartonella species previously detected in human cases in Thailand, such as B. henselae, B. tamiae, and B. vinsonii subsp. arupensis (Paitoonpong et al. 2008,

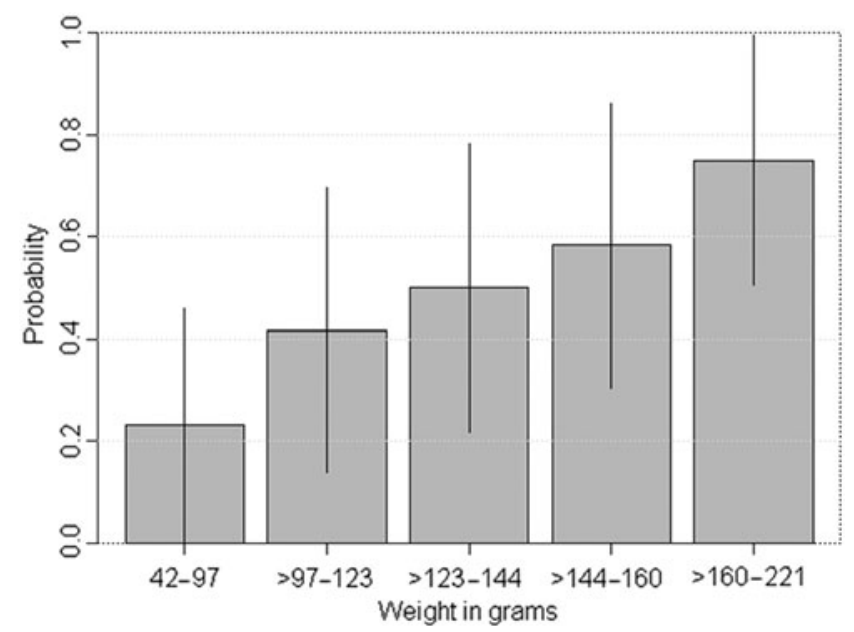

FIG. 3. Bartonella spp. prevalence by body length among $R$. tanezumi rats $(n=61)$ (Mekong Delta, Vietnam, October, 2012-March, 2013).
Kabeya et al. 2010, Bai et al. 2012), were not found in any of the rats examined in our study.

Our results suggest an increased prevalence of Bartonella spp. among older $R$. tanezumi. This suggests a cumulative risk and long-term carriage after infection, although the duration of persistence of infection in rats is unknown. These results contrast with previous studies of Bartonella spp. in other rat species, indicating that prevalence is inversely correlated with age (Fichet-Calvet et al. 2000, Kosoy et al. 2004, Jardine et al. 2006, Kosoy et al. 2008), although in a study on trapped $R$. norvegicus the prevalence of $B$. rattimassiliensis and $B$. phoceensis increased with rat weight (Gundi et al. 2004).

We observed a statistical association between Bartonella spp. positivity and the presence of Trombiculini-Blankaartia and Schoengastiini-Ascoschoengastia chiggers, suggesting that these species may play a role in the transmission of Bartonella spp. The finding of a higher prevalence of Bartonella spp. in rats with higher chigger burdens gives further support to this hypothesis, as trombiculid mites appear to be some of the most common ectoparasites on rats in the Mekong Delta. Unfortunately we could not confirm the identity of the Bartonella species in chiggers, because different genes were targeted on Bartonella spp. rats and chiggers ( $g l t A$ and $s s r A$, respectively). The reason was a low sensitivity of detection of Bartonella spp. in chiggers based on gltA gene testing (data not shown).

These results should be interpreted with caution and should be followed by relevant studies to investigate the mites' vector competence and to establish the cycle of transmission (transovarial, transtadial, etc.). Trombiculid chiggers are thought to feed after attaching themselves firmly to their hosts' skin by a feeding tube (stylostome). Therefore, transmission of Bartonella spp. to the rat host would only be theoretically possible if transovarial transmission occurs. The finding of Bartonella spp.-positive chiggers on noninfected rats is strongly suggestive of transovarial transmission.

Because a number of trombiculid species have been reported to feed on humans (Shatrov and Kudryashova 2006), it is at least theoretically possible that infected chiggers that have not yet completed their attachment to the rodents' skin may migrate to a human during the process of catching, slaughtering, and dressing live rats. Therefore, these occupationally exposed communities may potentially be at risk should they not take the necessary precautions to protect themselves from chigger mite bites. Newly hatched chiggers questing for available hosts in the surroundings of rat nesting areas may also pose a risk to humans. $R$. tanezumi, and to a lesser extent $R$. norvegicus, which are common in areas of human dwelling may therefore represent the greatest risk.

To date no Bartonella spp. infections have been detected in patients in Vietnam. This is in part likely to be the result of limited awareness of this infection among the medical community, partly as a result of a diffuse, nonspecific clinical picture. We suggest that Bartonella spp. infections may be more common than previously thought in Vietnam given the widespread presence of rats in close proximity to human habitats, of which a fraction are infected with pathogenic Bartonella spp., as well as rat trade-related practices that may facilitate human contact with vectors of Bartonella spp. infection. 


\section{Acknowledgments}

The authors would like to thank staff from the SubDepartment of Animal Health of Dong Thap for providing logistic assistance in carrying out field and laboratory work. Work was partly funded by the Vietnam Initiative on Zoonotic Infections (VIZIONS) (grant no. WT/093724), part of the Wellcome Trust Major Overseas Programme (United Kingdom), and the Li-Ka-Shing Foundation (083GR).

\section{Author Disclosure Statement}

No competing financial interests exist.

\section{References}

American Veterinary Medical Association (AVMA). AVMA guidelines on euthanasia. Available at https://www.avma.org/ $\mathrm{KB} /$ Policies/Documents/euthanasia.pdf. Last accessed August 4, 2014.

Angelakis E, Khamphoukeo K, Grice D, Newton PN, et al. Molecular detection of Bartonella species in rodents from the Lao PDR. Clin Microbiol Infect 2009; 15(Suppl 2):95-97.

Bai Y, Kosoy MY, Lerdthusnee K, Peruski LF, et al. Prevalence and genetic heterogeneity of Bartonella strains cultured from rodents from 17 provinces in Thailand. Am J Trop Med Hyg 2009; 81:811-816.

Bai Y, Kosoy MY, Diaz MH, Winchell J, et al. Bartonella vinsonii subsp arupensis in Humans, Thailand. Emerg Infect Dis 2012; 18:989-991.

Bhengsri S, Baggett HC, Peruski LF Jr, Morway C, et al. Bartonella spp. infections, Thailand. Emerg Infect Dis 2010; 16:743-745.

Boulouis HJ, Chang CC, Henn JB, Kasten RW, et al. Factors associated with the rapid emergence of zoonotic Bartonella infections. Vet Res 2005; 36:383-410.

Breitschwerdt EB, Kordick DL. Bartonella infection in animals: Carriership, reservoir potential, pathogenicity, and zoonotic potential for human infection. Clin Microbiol Rev 2000; 13:428-438.

Castle KT, Kosoy M, Lerdthusnee K, Phelan L, et al. Prevalence and diversity of Bartonella in rodents of northern Thailand: A comparison with Bartonella in rodents from southern China. Am J Trop Med Hyg 2004; 70:429-433.

Ceropath. Protocols for Field and Laboratory Rodent Studies. Bangkok: Kasetsart University Press, 2011. Available at www .ceropath.org/FichiersComplementaires/Herbreteau_Rodents_ protocols_2011.pdf

Chomel BB, Kasten RW. Bartonellosis, an increasingly recognized zoonosis. J Appl Microbiol 2010; 109:743-750.

Daly JS, Worthington MG, Brenner DJ, Moss CW, et al. Rochalimaea elizabethae sp. nov. isolated from a patient with endocarditis. J Clin Microbiol 1993; 31:872-881.

Diaz MH, Bai Y, Malania L, Winchell JM, et al. Development of a novel genus-specific real-time PCR assay for detection and differentiation of Bartonella species and genotypes. J Clin Microbiol 2012; 50:1645-1649.

Fichet-Calvet E, Jomaa I, Ben Ismail R, Ashford RW. Patterns of infection of haemoparasites in the fat sand rat, Psammomys obesus, in Tunisia, and effect on the host. Ann Trop Med Parasitol 2000; 94:55-68.

Gundi VA, Davoust B, Khamis A, Boni M, et al. Isolation of Bartonella rattimassiliensis sp. nov. and Bartonella phoceensis sp. nov. from European Rattus norvegicus. J Clin Microbiol 2004; 42:3816-3818.
Gundi VA, Taylor C, Raoult D, La Scola B. Bartonella rattaustraliani sp. nov., Bartonella queenslandensis sp. nov. and Bartonella coopersplainsensis sp. nov., identified in Australian rats. Int J Syst Evol Microbiol 2009; 59:29562961.

Hosmer D, Lemeshow S. Applied Logistic Regression. Wiley, 2004.

Hsieh JW, Tung KC, Chen WC, Lin JW, et al. Epidemiology of Bartonella infection in rodents and shrews in Taiwan. Zoonoses Public Health 2010; 57:439-446.

Jardine C, Waldner C, Wobeser G, Leighton FA. Demographic features of Bartonella infections in Richardson's ground squirrels (Spermophilus richardsonii). J Wildl Dis 2006; 42:739-749.

Jiyipong T, Jittapalapong S, Morand S, Raoult D, Rolain JM. Prevalence and genetic diversity of Bartonella spp. in small mammals from Southeastern Asia. Appl Environ Microbiol 2012; 78:8463-8466.

Kabeya H, Colborn JM, Bai Y, Lerdthusnee K, et al. Detection of Bartonella tamiae DNA in ectoparasites from rodents in Thailand and their sequence similarity with bacterial cultures from Thai patients. Vector Borne Zoonotic Dis 2010; 10:429-434.

Kamani J, Morick D, Mumcuoglu KY, Harrus S. Prevalence and diversity of Bartonella species in commensal rodents and ectoparasites from Nigeria, West Africa. PloS Negl Trop Dis 2013; 7:e2246.

Kosoy M, Mandel E, Green D, Marston E, et al. Prospective studies of Bartonella of rodents. Part I. Demographic and temporal patterns in population dynamics. Vector Borne Zoonotic Dis 2004; 4:285-295.

Kosoy M, Morway C, Sheff KW, Bai Y, et al. Bartonella tamiae sp. nov., a newly recognized pathogen isolated from three human patients from Thailand. J Clin Microbiol 2008; 46:772-775.

Kosoy M, Bai Y, Sheff K, Morway C, et al. Identification of Bartonella infections in febrile human patients from Thailand and their potential animal reservoirs. Am J Trop Med Hyg 2010; 82:1140-1145.

Kosoy M, Hayman DT, Chan KS. Bartonella bacteria in nature: Where does population variability end and a species start? Infect Genet Evol 2012; 12:894-904.

Kosoy MY. Ecological associations between bacteria of the genus Bartonella and mammals. Biol Bull 2010; 37:716-724.

Lerdthusnee K, Khlaimanee N, Monkanna T, Sangjun N, et al. Efficiency of Leptotrombidium chiggers (Acari: Trombiculidae) at transmitting Orientia tsutsugamushi to laboratory mice. J Med Entomol 2002; 39:521-525.

Lim MH, Chung DR, Kim WS, Park KS, et al. First case of Bartonella quintana endocarditis in Korea. J Korean Med Sci 2012; 27:1433-1435.

Lin JW, Chen CY, Chen WC, Chomel BB, et al. Isolation of Bartonella species from rodents in Taiwan including a strain closely related to 'Bartonella rochalimae' from Rattus norvegicus. J Med Microbiol 2008; 57:1496-1501.

Loan HK, Lien TX, Kosoy M, Lien DT, et al. Investigation of Bartonella bacteria in rodents in southern Vietnam. [in Vietnamese]. J Prevent Med XXI 2011; 6:201-206.

Maguiña C, Ordaya E. Bartonellosis: Carrion's disease and other Bartonella Infections. In: Mandell G, Bennet J, Dolin R, eds. Principles and Practice of Infectious Diseases. Philadelphia: Churchill Livingstone Elsevier, 2010.

Nadchatram M, Dohany A. A pictorial key to the subfamilies, genera and subgenera of Southeast Asian chiggers (Acari, 
Prostigmata, Trombiculidae). Bull Inst Med Res Malaysia 1974; 16:1-67.

Pachirat O, Kosoy M, Bai Y, Prathani S, et al. The first reported case of Bartonella endocarditis in Thailand. Infect Dis Rep 2011; 3 .

Paitoonpong L, Chitsomkasem A, Chantrakooptungool S, Kanjanahareutai S, et al. Bartonella henselae: First reported isolate in a human in Thailand. Southeast Asian J Trop Med Public Health 2008; 39:123-129.

Phan TT, Tam NT, Khai LT, Ogaswara N, et al. Prevalence of Salmonella spp. in rice field rats in the Mekong delta, Vietnam. J Vet Epidemiolo 2005; 9:85-88.

Shatrov A, Kudryashova N. Taxonomy, life cycles and the origin of parasitism in trombiculid mites. In: Morand S, Krasnov B, Poulin R, eds. Micromammals and Macroparasites. New York: Springer, 2006.

Traub R, Wisseman CL, Jr. The ecology of chigger-borne rickettsiosis (scrub typhus). J Med Entomol 1974; 11:237-303.
Winoto I, Goethert H, Nurisa Ibrahim I, Yuniherlina Y, et al. Bartonella species in rodents and shrews in the Greater Jakarta area. Southeast Asian J Trop Med Public Health 2005; 36:1523-1529.

Ying B, Kosoy MY, Maupin GO, Tsuchiya KR, et al. Genetic and ecologic characteristics of Bartonella communities in rodents in southern China. Am J Trop Med Hyg 2002; 66:622-627.

Address correspondence to:

Juan J. Carrique-Mas

Oxford University Clinical Research Unit Wellcome Trust Major Overseas Programme 764 Vo Van Kiet, Ward 1, District 5 Ho Chi Minh City Vietnam

E-mail: jcarrique-mas@oucru.org 